\title{
Primary progressive aphasia
}

INSERM

\section{Source}

INSERM. (1999). Orphanet: an online rare disease and orphan drug data base. Primary progressive aphasia. ORPHA:95432

Primary progressive aphasia (PPA) is a neurodegenerative disorder, characterized by a primary dissolution of language, with relative sparing of other mental faculties for at least the first 2 years of illness. PPA is recognized as the language variant in the frontotemporal dementia (FTD; see this term) spectrum of disorders. PPA can be classified into 3 subtypes based on specific speech and language features: semantic dementia (SD), progressive non-fluent aphasia (PNFA) and logopenic progressive aphasia (Iv-PPA) (see these terms). 